\title{
Cerebral biopsy in the investigation of presenile dementia due to cerebral atrophy
}

\author{
D NEARY, JS SNOWDEN, DM BOWEN,* NR SIMS,* DMA MANN, $\dagger$ PO YATES, $\dagger$ \\ AN DAVISON*
}

From the Departments of Neurology, Manchester Royal Infirmary, Department of Neuropathology, $\dagger$ University of Manchester and the Department of Neurochemistry, ${ }^{*}$ Institute of Neurology, London, UK

SUMMARY Investigation by cerebral biopsy of patients with dementia associated with cerebral atrophy permits the examination of clinico-pathochemical relationships, and provides a means of distinguishing and classifying forms of cerebral atrophy. Benefits of the procedure must however be weighed against possible adverse effects of surgical intervention. The study examines the outcome following biopsy of 24 patients with presenile dementia. No major operative complications were encountered, and recovery was uneventful in all but a single patient. The relevance of the findings to the study of dementia by cerebral biopsy is discussed.

The diagnosis and classification of cerebral atrophy in the presenium is imprecise, since clinical differentiation depends upon accurate neuropsychological characterisation and neuropathological and biochemical correlation. Necropsy investigations inevitably are of terminal pathological change and complete neurochemical analysis is prejudiced by post-mortem tissue autolysis. Moreover, patients in the advanced stage of disease may not be psychologically testable, and thus clinical distinctions between patients may not be evident.

Investigations of patients with presenile dementia in relatively early stages of disease by use of cerebral biopsy ${ }^{12}$ have been informative. Nevertheless, there is reluctance to resort to invasive procedures if an effective treatment is lacking. Recent findings of neurochemical deficits in patients with Alzheimer's disease have however opened up the possibility of symptomatic treatment, increasing the need for accurate definition of patient groups. Clinical studies without pathochemical verification may be misleading.

Benefits arising from accurate diagnosis must however be weighed against potential risks of biopsy. Objection to the procedure would be justified if

Address for reprint requests: Dr D Neary, Department of Neurology, Manchester Royal Infirmary, Manchester M13 9WL, UK

Received 11 December 1984 and in revised form 22 June 1985. Accepted 27 June 1985 accelerated deterioration followed surgical intervention. This paper presents information regarding the outcome of 24 patients who have undergone cerebral biopsy for investigations of primary degenerative dementia in the presenium. The investigations were designed to differentiate forms of cerebral atrophy and their pathogenesis by examining the relationship between neuropsychological, pathological and biochemical data, and to identify patients with Alzheimer's disease in order to include them in therapeutic trials using oral choline and a parenteral cholinergic agonist.

\section{Methods}

\section{Selection of patients}

The 24 patients, previously described ${ }^{3}$ represent a subsection of patients investigated with a clinical diagnosis of primary cerebral atrophy. They were relatively youthful and otherwise physically well, and their relatives were educated, supportive and highly motivated to seek diagnosis and possible treatment. The progressive nature of the patient's condition was explained to relatives, and the use of biopsy as a means of defining the precise nature of the disease. Relatives were informed of potential surgical risks and that the intent of the investigations was directed toward greater understanding and possible treatment, and that the procedure was diagnostic and not itself therapeutic. It was emphasised that any resulting therapeutic trials would have no guarantee of success and would likely to be symptomatic rather than curative. Cerebral biopsy was carried out at the request and with the written consent of close relatives, only after the issues had been discussed at length with family and friends. 
Table 1 Outcome following cerebral biopsy

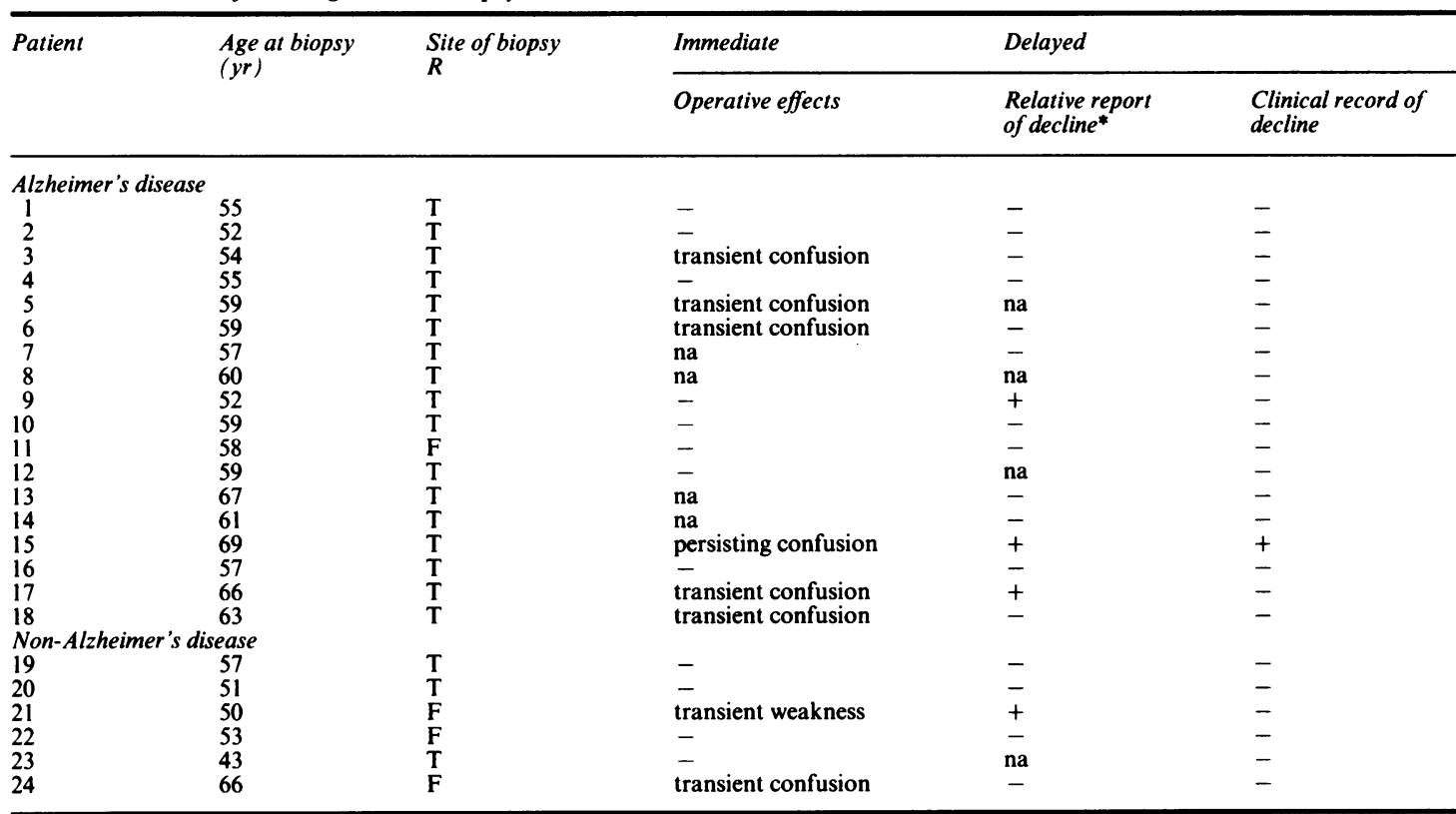

$\mathrm{T}=$ temporal lobe; $\mathbf{F}=$ frontal lobe

na $=$ information not available

* relative's report of deterioration in day-to-day activities on discharge. Deterioration may reflect specific effects of biopsy, non-specific effect of hospitalization, or natural history of disease.

Ethical consent

The procedure of cerebral biopsy was agreed by the Manchester Central District Ethical Committee.

\section{Surgical procedure}

The procedure was carried out by a single senior neurosurgeon. Tissue was obtained from the right temporal lobe by means of a temporal lobe flap. In the final four cases a burr-hole procedure was adopted and tissue obtained from the right frontal lobe, since this is a more circumscribed procedure, and entails a shorter length of anaesthesia. The approximate weight of the cortical tissue was 1 and $1.25 \mathrm{~g}$ for frontal and temporal biopsy respectively.

\section{Assessment of outcome}

Immediate and long-term effects of cerebral biopsy were evaluated with respect to the following criteria:

(1) post-operative morbidity, (2) relatives' assessment of patients' mental state, (3) clinical assessment before and after biopsy, (4) long term prognosis

\section{Outcome}

\section{Morbidity}

There were no major operative complications, and no patient suffered a post-operative bleed or intracranial infection (table 1). One patient sustained a transien and minimal weakness of the left arm which had to tally resolved within 7 days. Rapid post-operative recovery occurred in the majority of patients. In eight post-operative confusion occurred, resolving within 1-7 days in all but one Alzheimer's disease patient. This latter patient, aged 69 years, and the eldest in the. series had demonstrated markedly dilated ventricles on computer tomography, and had presented a clinical syndrome suggesting an alternative diagnosis of communicating hydrocephalus. ${ }^{3}$ At the time of biopsy his dementia was severe. A fluctuating confusion persisted over the ensuing months.

\section{Relatives' reports}

Some time after the patient's admission relatives completed a short questionnaire, purportedly designed to assess patients' reactions to a hospital stay. Critical questions were of the type "Were there tasks that he/she could no longer do on returning home?" These "negative" questions were balanced by "positive" questions of the type "Was there improvement in his/her condition after a hospital rest?". Questions were included regarding the patient's emotional reac- 
tion during the hospital stay 'Was he/she upset by the stay?". Neutral questions were interspersed: "How long was the stay?".

In order to distinguish possible specific effects of the operative procedure from the general effects of altering the routine of a demented person by hospitalisation responses were obtained also from relatives of 20 patients admitted for investigation of dementia without cerebral biopsy. It was not however possible to match groups accurately. Owing to the more extensive investigations in the biopsied patients duration of hospital stay was longer, with an average length of stay of 17 days compared to 7 days in non-biopsied patients. In patients undergoing biopsy the dementia tended to be more severe.

Deterioration in the patients' condition on early return from hospital was reported by relatives in 4/20 $(20 \%)$ biopsy cases (table 1). In two of these instances, (patients 9 and 21 , table 1) subsequent improvement was reported, on readjustment to the home environment. Both patients had been emotionally and socially disturbed by hospital admission prior to biopsy. In the other two cases (patients 15 and 17) the deterioration was regarded by relatives as sustained. Improvement following hospital discharge was reported in one biopsy case. For non-biopsied patients, relatives reported a deterioration in $2 / 20$ $(10 \%)$ patients, sustained in one case and temporary in the other, and an improvement in 10/20 (50\%) cases.

\section{Follow-up assessments}

Neuropsychological clinical ratings ${ }^{3}$ of patients prior to their discharge from hospital revealed that with the exception of the single patient with persisting confusion (patient 15, table 1) all had regained their previous rated level of functioning. No aspect of disability was detected following biopsy that had not been present prior to surgery.

Six-monthly review of patients currently being carried out includes assessment of orientation, object naming, verbal fluency, object recognition, block constructions, immediate and reversed digit span and immediate and delayed memory for name and address. These items were selected from the full clinical mental examination ${ }^{3}$ since (a) they sample the spectrum of disability found in the patient group, (b) they are sensitive to change, while avoiding floor and ceiling level performance in the patient population, (c) performance can be easily quantified and (d) alternate versions are readily devised, matched for difficulty and suitable for multiple repeat testing. Cumulative scores from individual items (maximum $=50$ ), are depicted in fig la, pre and post-biopsy for six Alzheimer's disease and two non-Alzheimer's disease patients in whom long-term follow-up data are avail- able. Pre-biopsy scores correlate significantly with clinical rating of impairment $(r=-0.91, p<0.001)$ and with full scale WAIS scores $(r=0.78, p<0.02)$. Figure Ib shows scores for a group of non-biopsied patients with clinically presumed Alzheimer's disease, matched with the biopsied Alzheimer's disease group in terms of their pattern of cognitive deficits and clinically rated severity of dementia on initial testing. Their mean age on initial examination was 60 years, range 54-67; their mean duration of illness 3 years, range 1-6 years. The scores, based however on unweighted measures, should appropriately be regarded

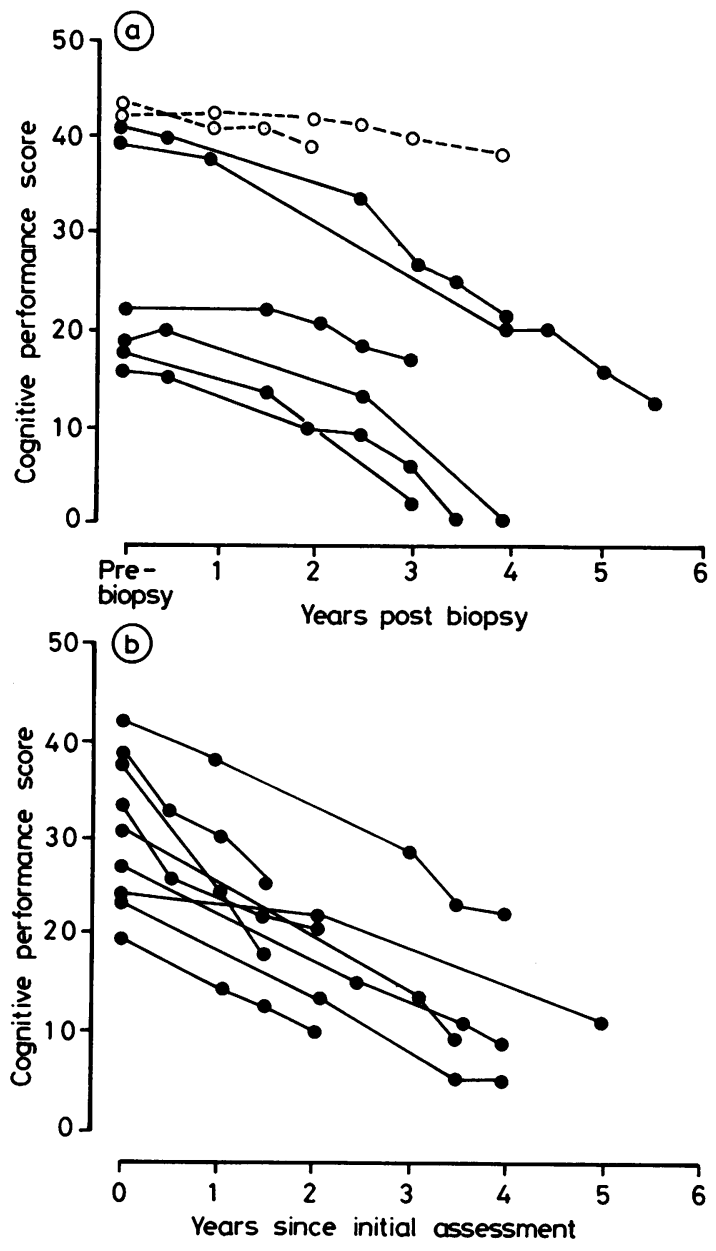

Fig 1 (a) Cognitive performance scores before biopsy and at intervals after biopsy in six Alzheimer's disease patients (-) and two non-Alzheimer's disease patients (...). The following patients are represented (respectively in descending order of pre-biopsy performance): nos. 19, 21, 18, 17, 14, 2, 10, 9. (b) Cognitive performance scores at intervals since initial assessment in non-biopsied patients with clinically presumed Alzheimer's disease. 
as "ranks" lying on an ordinal rather than interval scale, thus restricting the conclusions that can presently be drawn with respect to "gradient" of cognitive decline. Nevertheless the graphic representations do mirror the clinical observation firstly that the course of disease is not uniform across patients, and secondly that the course in biopsied patients is not substantially different from that in non-biopsied patients. A Mann-Whitney U test comparing biopsied and nonbiopsied Alzheimer's disease patients on initial testing did not reveal a significant difference between ranks in the two groups. A comparison of ranks after 18 months again revealed no group difference. Figure la includes data on those three patients in whom a deterioration had been reported by relatives following biopsy, but not observed clinically (nos. 9.17 and 21).

\section{Prognosis}

The length of time since biopsy ranges from 1 to 5 years, mean 3 years. Of the 18 patients showing the pathological changes of Alzheimer's disease two have died in the interim, 1 and 2 years after biopsy, with a total duration of illness of 3 and 7 years respectively (table 2). The duration of illness in surviving patients ranges from 3 to 12 years, mean 7 years. Of the six patients classified as non-Alzheimer's disease on the basis of biopsy findings one has died, 3 years following the procedure and with a total duration of illness of 9 years. The mean duration of illness in surviving patients is 6 years, range $3-8$ years.

The occurrence of epileptic seizures has been reported in four Alzheimer's disease patients. One patient had a generalised convulsion 1 year prior to biopsy, and a second attack 3 years after biopsy. An attack was reported in a second patient 2 months after biopsy, in a third patient 1 year, and in a fourth patient 3 and 5 years after biopsy. In the nonAlzheimer's disease group convulsive episodes were described after biopsy in one patient. Owing to the infrequency of seizures no patient required long-term anti-convulsant medication.

\section{Discussion}

Cerebral biopsy has been undertaken in 24 patients for investigation of their dementia. No major operative complications were encountered, in keeping with findings ${ }^{4}$ that it is a relatively safe procedure. Immediate effects of the procedure were confined to transient post-operative confusion in a minority of patients. This resolved in all but a single male $\mathrm{Al}$ zheimer's disease patient, in whom a diagnosis of communicating hydrocephalus had been considered. A poor outcome has been reported in clinically similar patients with Alzheimer's disease following cerebral biopsy and ventricular shunting. ${ }^{2}$

Table 2 Outcome following cerebral biopsy - long-term

\begin{tabular}{lllll}
\hline Patient & $\begin{array}{l}\text { Duration of illness } \\
\text { at biopsy (years) }\end{array}$ & $\begin{array}{l}\text { Seizures recorded } \\
\text { (number) }\end{array}$ & $\begin{array}{l}\text { Duration of illness } \\
\text { at time of first fit }\end{array}$ & $\begin{array}{l}\text { Present status of } \\
\text { patient } \\
H I D\end{array}$
\end{tabular}

\begin{tabular}{|c|c|c|c|c|}
\hline $\begin{array}{ll}\text { Alzheimer's disease } \\
1 \\
2 & 1 \\
3 & 2 \\
4 & 2 \\
5 & 5 \\
6 & 7 \\
7 & 2 \\
8 & 4 \\
9 & 5 \\
10 & 3 \\
11 & 3 \\
12 & 3 \\
13 & 8 \\
14 & 2 \\
15 & 1 \\
16 & 1 \\
17 & 3 \\
18 & 6 \\
\text { Non-Alzheimer's disease } \\
19 & 5 \\
20 & 3 \\
21 & 4 \\
22 & 3 \\
23 & 7 \\
24 & 6 \\
& 2\end{array}$ & $\begin{array}{l}\text { none } \\
2 \\
\text { none } \\
2 \\
1 \\
\text { none } \\
\text { none } \\
\text { none } \\
\text { none } \\
\text { none } \\
\text { none } \\
? \\
\text { none } \\
\text { none } \\
\text { none } \\
1 \\
\text { none } \\
\text { none } \\
\text { none } \\
1 \\
\text { none } \\
\text { none } \\
\text { none }\end{array}$ & $\begin{array}{l}4 \\
7\end{array}$ & 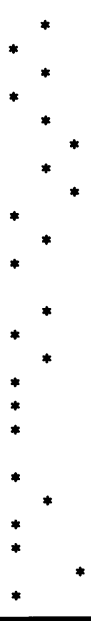 & $\begin{array}{c}6 \\
7 \\
7 \\
10 \\
11 \\
3 @ \\
8 \\
7 @ \\
6 \\
5 \\
4 \\
12 \\
5 \\
3 \\
3 \\
6 \\
11 \\
8 \\
7 \\
7 \\
4 \\
8 \\
9 @ \\
3\end{array}$ \\
\hline
\end{tabular}

Abbreviations: $\mathbf{H}=$ patient still living at home; $\mathbf{I}=$ patient in institutional care; $\mathbf{D}=$ patient deceased. 
Early clinical evaluation in other patients following biopsy revealed no evidence of a deterioration in their mental state. Formal reassessment, however, necessarily takes place following a period of post-operative convalescence, so that possible effects of the biopsy procedure are confounded with the effects of natural progression of the disease. An adverse effect of biopsy would however lead to the prediction of a greater decline in cognitive performance during the 6 month period during which biopsy took place than in subsequent 6 month periods, and/or a more rapid rate of progression of disease compared to non-biopsied patients. Longitudinal follow-up of patients suggests neither of these predictions to be the case. Cognitive performance scores, while correlating significantly with clinical ratings of impairment and WAIS scores should nevertheless be regarded as ordinal, and thus reflect decline rather than accurately measure rate of change over specified time intervals. Both the biopsied Alzheimer's disease patients and those in the non-biopsied comparison group of putative Alzheimer's disease patients, depicted in figure $1 \mathrm{~b}$, have participated in the same therapeutic trials during the period of follow-up, and therefore any drug effects ought to be reflected in both groups.

Reports by relatives provide some account of the patient's functioning. Yet, interpretation of such reports may itself be unreliable. Disruption of domestic routine may result in a deterioration independently of in-patient investigations. Relatives' perceptions may be coloured by their expectations. For example, questionnaire responses by relatives of biopsied and nonbiopsied patients differed less in terms of perceived deterioration than in terms of perceived improvement following the patient's hospital admission, yet clinical improvement was not apparent in any patient. A deterioration following discharge from hospital was reported in four biopsied patients. For only one patient did relatives' observations mirror the clinically rated findings. For other patients, there was no clinical evidence to corroborate the relatives' reports of a deterioration.

While seizures are a feature known to occur in the late stages of Alzheimer's disease, incidence of fits among the Alzheimer's disease population is not precisely known. In one study ${ }^{5}$ seizures were recorded in $5 / 33(15 \%)$ of patients with a clinical diagnosis of primary degenerative dementia of the Alzheimer type. In another study ${ }^{2}$ a history of recurrent seizures was recorded in $2 / 10(20 \%)$ patients. In the present series seizures were reported in $5 / 24(21 \%)$ of patients, but in no patient were these recurrent requiring long-term treatment.

The length of survival in Alzheimer's disease is often regarded as 7 years, although reports suggest that a wide variation exists, ranging from 1 to 20 years. $^{6}$
Long-term follow up of biopsied patients provides no evidence that the procedure has significantly altered their life expectancy. One patient died with a total length of history of only 3 years. Yet, his course had been rapid prior to biopsy, and there was no suggestion that the rate of decline had increased following the procedure. Most other patients are alive several years following biopsy, and many have surpassed their "predicted" 7 year life expectancy.

In conclusion, examination of a series of 24 patients, who have undergone cerebral biopsy for investigation of their dementia, has revealed no convincing evidence for permanent or accelerated adverse effects post-operatively apart from in one patient. The findings support the view that cerebral biopsy is a relatively safe procedure, provided rigorous standards are applied, ensuring the minimum time under general anaesthesia, the obtaining of minimal tissue possible for analysis, by a single senior neurosurgeon, who is aware of the tissue requirement but is nevertheless the sole arbiter of the minimal scale of dissection.

The results of clinical, pathological and chemical data obtained from this group of patients have indicated that cerebral atrophy is a heterogeneous group of disorders of which Alzheimer's disease is the most common. However, the clinical presentation of Alzheimer's disease in the presenium is not uniform, and patients without Alzheimer's disease may share clinical characteristics similar to those of Alzheimer's disease. ${ }^{3}$ Correlative studies in Alzheimer's disease have permitted comment on the relative contributions of cortical and subcortical disorders in the dementia of Alzheimer's disease. ${ }^{7}$ The availability of tissue from cerebral biopsy permits the possibility of examining many major neurotransmitters including glutamic acid. ${ }^{8}$ Patients with proven Alzheimer's disease have entered therapeutic trials of orally administered choline and a parenterally administered cholinergic agonist.

We are grateful for financial support to the Medical Research Council, the Brain Research Trust, the Miriam Marks Charitable Trust and the North West Regional Health Authority.

\section{References}

${ }^{1}$ Sim M, Turner S, Smith WT. Cerebral biopsy in the investigation of presenile dementia. $\mathrm{Br} J$ Psychiatry 1966;112:119-25.

${ }^{2}$ Coblentz JM, Mattis S, Zingesser LH, Kasoff SS, Wisniewski HM, Katzman R. Presenile dementia: clinical aspects and evaluation of cerebrospinal fluid dynamics. Arch Neurol 1973;29:299-308.

${ }^{3}$ Neary D, Snowden JS, Bowen DM, et al. Neuro- 
psychological syndromes in presenile dementia due to cerebral atrophy. J Neurol Neurosurg Psychiatry 1986;49:163-74.

${ }^{4}$ Spillane JA. Alzheimer's disease: a state of cholinergic deficiency? MD thesis, University of London, 1978.

${ }^{5}$ Seltzer B, Sherwin I. A comparison of clinical features in early- and late-onset primary degenerative dementia. Arch Neurol 1983;40:143-6.

${ }^{6}$ Lauter H. Zur Klinik und Psychopathologie der Al- zheimerschen Krankheit. Psychiatria Clinica 1968;1:85-108.

${ }^{7}$ Neary D, Snowden JS, Bowen DM, Sims NR, Mann DMA, Northen B, Yates PO, Davison AN. Alzheimer's disease: a correlative study. J Neurol Neurosurg Psychiatry 1986;49. (in press).

${ }^{8}$ Bowen DM, Davison AN. Biochemical studies of nerve cells and energy metabolism in Alzheimer's disease. $\mathrm{Br}$ Med Bull 1985, (in press). 